удК 347.78

\author{
Е. Г. Белькова \\ Иркутский институт (филиал) \\ Всероссийского государственного университета юстиции \\ (РПА Минюста России), \\ 2. Иркутск, Российская Федерация \\ В. Н. Белоусов \\ Байкальский государственный университет, \\ г. Иркутск, Российская Федерация
}

\title{
АВТОР КАК СУБЪЕКТ ДОГОВОРА АВТОРСКОГО ЗАКАЗА
}

\begin{abstract}
АНнотАЦия. В статье определен круг основных проблем, связанных с установлением субъектного состава, выступающего на стороне автора произведения по договору авторского заказа. Поддержана позиция, согласно которой автором по данному договору является исключительно физическое лицо. Обосновано, что в Гражданском кодексе Российской Федерации не предусмотрен договор заказа на создание результата интеллектуальной деятельности, в котором создателем произведения могло бы выступать юридическое лицо. В этой связи аргументировано предложение о возможности применения по аналогии норм о договоре авторского заказа в случае выступления исполнителем договорного обязательства по созданию объекта авторского права юридического лица. Вместе с тем уточнено, что при регулировании данных отношений не должны применяться нормы, которые усиленно защищают слабую сторону в договоре, т.е. гражданина - автора. Подтверждена целесообразность нормы закона, устанавливающей право несовершеннолетнего, достигшего четырнадцати лет, осуществлять права автора произведения без согласия законных представителей.

кЛЮчЕВЫЕ СЛОВА. Договор авторского заказа; автор; заказчик; гражданин; юридическое лицо; субъектный состав; произведение.

ИНФОРМАЦИЯ О СТАТЬЕ. Дата поступления 16 января 2017 г.; дата принятия к печати 1 февраля 2017 г.; дата онлайн-размещения 31 марта 2017 г.
\end{abstract}

E. G. Belkova

Irkutsk Institute (branch), All-Russian State University of Justice (Ministry of Justice of the Russian Federation), Irkutsk, Russian Federation

V. N. Belousov

Baikal State University,

Irkutsk, Russian Federation

\section{AUTHOR AS A SUBJECT OF COMMISSIONING AGREEMENT}

ABSTRACT. The article specifies the range of issues connected with establishing contracting parties siding the author of a piece of work under the commissioning agreement. It supports a position according to which an exceptionally natural person is the author under this agreement. It substantiates that the Civil Code of the Russian Federation does not envisage the commissioning agreement for creating an intellectual activity result in which the legal entity can act as the creator of a piece of work. In view of this, it gives reasons for possibility of using in terms of the analogy the norms of the commissioning agreement in case the legal entity act as the executor of the commissioning agreement in creating the copyrighted item. Along with that, it specifies that in regulating these relations one must not use the norms that intensely protect the weak party in the agreement, that is, the civilian - the author. It confirms the statuary provision expediency that establishes the right of a minor, achieving the age of fourteen years, to exercise the rights of the author of a piece of work without consent of legal representatives.

\section{Baikal Research Journal}


KEYWORDS. Commissioning agreement; author; customer; civilian; legal entity; contracting parties; piece of work.

ARTICLE INFO. Received January 16, 2017; accepted February 1, 2017; available online March 31, 2017.

В соответствии со ст. 1288 Гражданского кодекса РФ ${ }^{1}$ (далее - ГК РФ) договор авторского заказа заключается между автором и заказчиком.

Автором произведения науки, литературы или искусства признается гражданин, творческим трудом которого оно создано (ст. 1257 ГК РФ). Следовательно, по действующему российскому законодательству не предусмотрено участие юридических лиц в качестве автора произведения. Этот вывод созвучен мнению, высказанному в большинстве исследовательских работ $[1$, с. $217 ; 2$, с. $27 ; 3$, с. 29]. Согласно п. 1 ст. 1228 ГК РФ граждане, оказавшие автору только техническое, консультационное, организационное или материальное содействие, а также граждане, осуществлявшие контроль за выполнением соответствующих работ, не признаются авторами результата интеллектуальной деятельности. Однако вывод о том, что в качестве автора по договору авторского заказа следует рассматривать только гражданина не является единственным в доктрине гражданского права. Некоторые ученые в качестве исполнителя (автора) рассматривают как физических, так и юридических лиц $[4$, с. 59].

В судебной практике также отсутствует единый подход относительно возможности участия юридического лица на стороне автора по договору авторского заказа.

В Постановлении ФАС Московского округа от 2 ноября 2009 г. указывается, что со стороны автора может выступать только физическое лицо, творческим трудом которого создано произведение. Поэтому суд пришел к выводу, что договор о создании фотографического изображения, заключенный между ООО «Национальная логистическая компания» и ЗАО «Союздизайн» по своей правовой природе является договором подряда, а не договором авторского заказа ${ }^{2}$.

В Определении Верховного суда РФ от 1 апреля 2015 г. содержится противоположный вывод. Так, договор, заключенный между Фондом социальной и экономической поддержки отечественной кинематографии и Фондом поддержки культуры и искусства «Люблю и точка» о создании (производстве) художественного полнометражного национального фильма социально значимой тематики «Скобелев», суд квалифицировал как договор авторского заказа ${ }^{3}$.

Встречаются судебные решения, в которых в качестве автора по анализируемому договору суд рассматривает, в том числе и индивидуального предпринимателя. Например, договор, по которому индивидуальный предприниматель Фадеев М. А. должен по заданию заказчика - ООО «Индиго Продакшн» в соответствии с определенными характеристиками создать, а в последующем передать заказчику не менее 12 произведений на русском языке и не менее 12 произведений на английском языке, суд признал договором авторского заказа ${ }^{4}$.

Зарубежный опыт свидетельствует о возможности участия юридического лица на стороне автора. Например, в Германии создателем банка данных (аналог составного произведения, выделяемого в России) помимо физических лиц могут

${ }^{1}$ Гражданский кодекс Российской Федерации (часть четвертая) : федер. закон от 18 дек. 2006 г. № 230-Ф3 // Собрание законодательства РФ. 2006. № 52, 1 ч. Ст. 5496.

${ }^{2}$ Постановление ФАС Московского округа от 2 нояб. 2009 г. № КГ-А40/11184-09 по делу № A4051856/08-15-465 [Электронный ресурс] // СПС «КонсультантПлюс».

${ }^{3}$ Определение Верховного Суда РФ от 1 апр. 2015 г. № 305-ЭС14-8121 по делу № A40-140516/2013 [Электронный ресурс] // СПС «КонсультантПлюс».

${ }^{4}$ Постановление Суда по интеллектуальным правам от 22 июля 2014 г. № C01-639/2014 по делу № A40-138710/2013 [Электронный ресурс] // Там же.

\section{Baikal Research Journal}

электронный научный журнал Байкальского государственного университета 
выступать и юридические лица. Во Франции юридическое лицо может выступать в качестве автора в отношении коллективного произведения [5, с. 45].

Итак, закрепление в ГК РФ понятия «автор» не только не прекратило полемику о субъектном составе на стороне автора, но и послужило основанием для ее развития. Анализ точек зрения, высказанных в юридической литературе, а также позиций суда по рассматриваемым спорам послужил основанием для следующего вывода. В качестве автора по договору авторского заказа должен выступать исключительно человек, поскольку только он обладает способностью заниматься творческой деятельностью. Даже в тех случаях, когда исполнителем в договоре авторского заказа указывается юридическое лицо, непосредственно осуществлять создание произведения будет гражданин, который состоит с данным юридическим лицом в трудовых отношениях и создает объект авторского права в рамках служебного задания, либо обязанность создания произведения для юридического лица может возникнуть в силу гражданско-правового договора. На этот счет интересная точка зрения высказана О. А. Рузаковой: «...исполнителем по договору заказа может быть как автор, так и иное лицо - посредник при создании результата, но фактическое создание объекта может осуществляться только физическим лицом» [6, с. 363]. Похожей позиции придерживается и Е. Н. Лукьянчикова [7, с. 27-28]. Юридические лица приобретают право использования указанных результатов на основании договоров об отчуждении исключительного права или лицензионных договоров, заключаемых лицом с обладателями исключительных прав на соответствующие результаты интеллектуальной деятельности. Поэтому авторами, например, кинофильма, в соответствии со ст. 1263 ГК РФ должны признаваться: автор сценария, режиссер-постановщик, композитор, а не юридическое лицо (киностудия).

Договор авторского заказа необходимо отличать от произведения науки, литературы или искусства, созданного в пределах, установленных для работника (автора) трудовых обязанностей (служебное произведение).Вызывает поддержку вывод Э. П. Гаврилова о том, что даже в тех случаях, когда гражданин осуществляет творческую деятельность по трудовому договору, заключенному с работодателем, или по его заданию, и этот работодатель (организация) получает права на созданное произведение, все равно организация не становится автором произведения. Авторские права первоначально возникают у автора - физического лица, а затем переходят к юридическому лицу [8].

Следовательно, юридическое лицо может приобретать исключительные права по договору с автором в результате выполнения гражданином служебного задания. Кроме того, право на произведение может возникнуть у юридического лица в силу наследования по завещанию.

Учитывая, что в гражданском законодательстве отсутствует договор заказа на создание результата авторского права, в котором создателем произведения могло бы выступать юридическое лицо, считаем возможным к таким отношениям по аналогии применять нормы о договоре авторского заказа. Вместе с тем при регулировании отношений с создателем - юридическим лицом не должны применяться нормы гл. 70 ГК РФ, которые усиленно защищают слабую сторону в договоре, т. е. гражданина - автора. Речь идет о том, что к таким отношениям не должны применяться нормы о льготном сроке исполнения договора, об ограниченной ответственности автора, об обязанности создать произведение лично.

Логичным представляется вывод А. С. Васильева о том, что договор авторского заказа заключается только с автором - физическим лицом. В том случае, если по договору юридическое лицо, используя навыки своих работников, принимает на себя обязательство в обусловленный договором срок создать произведение и

\section{Baikal Research Journal}

электронный научный журнал Байкальского государственного университета 
передать его заказчику, то такой договор не является договором авторского заказа. Данный договор можно квалифицировать как непоименованный договор, т. е. договор, законом не предусмотренный, но ему не противоречащий [9, с. 135].

Принимая во внимание, что в качестве автора могут выступать только физические лица, возникает вопрос: необходимо ли физическому лицу обладать правоспособностью и полной дееспособностью (правосубъектностью) для признания его автором произведения?

Авторские права на произведения науки, литературы и искусства входят в содержание правоспособности граждан (ст. 18 ГК РФ). Следовательно, для признания физического лица автором произведения не требуется достижения им определенного возраста и наличие дееспособности. А. П. Сергеев приводит интересные примеры, когда малолетние граждане становились авторами произведений: Н. Рушевой за свои 17 лет было создано 11 тыс. рисунков, состоялось 15 выставок ее работ; первый сборник стихов Н. Турбиной был опубликован, когда ей было всего 8 лет [10].

Вместе с тем заключить договор авторского заказа, осуществить права автора произведения науки, литературы и искусства в соответствии с пп. 2 п. 2 ст. 26 ГК РФ вправе без согласия законных представителей несовершеннолетний, достигший четырнадцати лет. На этот счет в доктрине гражданского права сложилось несколько мнений.

Согласно одному из них самостоятельным субъектом относительного авторского правоотношения должно быть только лицо, обладающее сделкоспособностью в полном объеме. В этой связи ученые формулируют вывод о необходимости запретить заключение договора авторского заказа с несовершеннолетними [11, с. 95].

Другое мнение состоит в том, что возможно заключение договора авторского заказа с несовершеннолетним, достигшим четырнадцати лет, с письменного согласия законных представителей. Свой вывод авторы мотивируют необходимостью защиты прав автора, не достигшего совершеннолетия [5, с. 46].

Высказан также вывод о том, что несовершеннолетний, достигший четырнадцати лет, вправе осуществлять права автора произведения науки, литературы и искусства без согласия законных представителей. Такой подход представляется более убедительным. Как справедливо отмечает А. П. Сергеев, несовершеннолетний, достигший четырнадцати лет, обладает достаточной зрелостью для разумного распоряжения достигнутыми им творческими результатами [10].

Следовательно, для того, чтобы выступать в качестве автора по договору авторского заказа гражданину необходимо достигнуть четырнадцатилетнего возраста. Как указывает О. А. Рузакова, в законодательстве не определены особенности распоряжения исключительными правами лицами, не достигшими четырнадцати лет, а также недееспособными гражданами [6, с. 217]. В соответствии с общими правилами, закрепленными в ГК РФ, за лицами, не достигшими четырнадцати лет, а также за недееспособными гражданами, авторские права осуществляют их законные представители (родители, опекуны). Ограниченно дееспособные граждане, согласно ст. 30 ГК РФ авторские права осуществляют с согласия попечителей.

Из буквального толкования ст. 1257 ГК РФ некоторые авторы сделали следующий вывод. Лицо, которое обязуется создать произведение по договору авторского заказа нельзя назвать автором, поскольку произведение еще не создано и нет гарантии того, что лицо исполнит свое обязательство и станет автором [11, с. 54]. Некоторые исследователи предлагают договор авторского заказа не именовать авторским, а создавать будущие произведения в рамках «договора на произведения, созданные по заказу», поскольку «авторское право регулирует лишь те отношения, которые возникают в связи с использованием уже созданного произведения»

\section{Baikal Research Journal}


[12, с. 73]. В связи с этим, ученые полагают, что до создания объекта авторского права сторона анализируемого договора может называться автором условно, и целесообразнее именовать соответствующую сторону договора - «лицо, чьим творческим трудом создано (создается) произведение» [Там же, с. 72] или «лицо, обязующееся создать произведение» [5, с. 44]. Учитывая, что отношения по созданию произведения науки, литературы, искусства в рамках договора авторского заказа регламентируют действия контрагентов до появления самого произведения, то данные отношения характеризуются указанными учеными как организационно-предпосылочные (образующие) [Там же].

Вопреки указанной позиции полагаем, что договор авторского заказа оправданно отнесен законодателем к числу самостоятельных авторских договоров. В предмет договора авторского заказа включается как создание произведения физическим лицом, так и передача заказчику исключительного права на этот объект. Вместе с тем необходимо учитывать, что гражданин становится автором и у него возникают авторские права с момента создания объекта авторского права.

Таким образом в качестве автора как субъекта договора авторского заказа может выступать только физическое лицо, творческим трудом которого создано произведение.

\section{Список использованной литературы}

1. Чапанов С.-М. С. Проблемы правового регулирования договора заказа на создание результатов интеллектуальной деятельности / С.-М. С. Чапанов // Транспортное дело России. - 2010. - № 9. - С. 215-219.

2. Хохлов В. А. Договор авторского заказа в гражданском праве России / В. А. Хохлов // Журнал российского права. - 2011. - № 4 (172). - С. 26-35.

3. Гаврилов Э. Договоры заказа на создание авторских произведений / Э. Гаврилов, К. Гаврилов // Хозяйство и право. - 2013. - № 3. - С. 28-45.

4. Степанова О. А. Передача авторских прав по договору / О. А. Степанова // Интеллектуальная собственность. Авторское право и смежные права. - 2002. - № 2. - С. 54-68.

5. Корчуганова Л. В. Специфика субъектного состава на стороне исполнителя по договору авторского заказа / Л. В. Корчуганова // Вопросы российской юстиции. - 2015. № 2 (2). - C. 43-47.

6. Рузакова О. А. Система договоров о создании результатов интеллектуальной деятельности и распоряжения исключительными правами: дис. ... д-ра юрид. наук : 12.00.03 / О. А. Рузакова. - М., 2007. - 497 с.

7. Лукьянчикова Е. Н. Commissioning agreements / Е. Н. Лукьянчикова // Патенты и лицензии. Интеллектуальные права. - 2012. - № 8. - С. 25-28.

8. Гаврилов Э. П. Юридические лица - авторы произведений / Э. П. Гаврилов // Патенты и лицензии. - 2006. - № 12. - С. 34-41.

9. Комментарий к Гражданскому кодексу Российской Федерации (учебно-практический) к части четвертой / под ред. С. А. Степанова. - 4-е изд. - М. : Проспект, 2015. - 456 с.

10. Сергеев А. П. Право интеллектуальной собственности в Российской Федерации / А. П. Сергеев. - М. : Проспект, 1996. - 704 с.

11. Рахматулина Р. Ш. Авторский договор с участием иностранных лиц: дис. ... канд. юрид. наук : 12.00.03 / Р. Ш. Рахматулина. - М., 2002. - 156 с.

12. Сорокина Л. В. Автор как сторона авторского договора и договора авторского заказа / Л. В. Сорокина // Вестник Челябинского государственного университета. Сер.: Право. -2008 . - № 22 . - С. $72-76$.

\section{References}

1. Chapanov S.-M. S. Problems of legal regulation of commissioning agreements on creating results of intellectual activity. Transportnoe delo Rossii = Transport Business of Russia, 2010, no. 9, pp. 215-219. (In Russian).

2. Khokhlov V. A. Commissioning agreements in Russian Civil Law. Zhurnal rossiyskogo prava = Journal of Russian Law, 2011, no. 4 (172), pp. 26-35. (In Russian).

\section{Baikal Research Journal}


3. Gavrilov Ye., Gavrilov K. Commissioning agreements on creating authors' pieces of work. Khozyaistvo $i$ pravo = Economy and Law, 2013, no. 3, pp. 28-45. (In Russian).

4. Stepanova O. A. Transfer of author's rights under agreement. Avtorskoe pravo i smezhnye prava $=$ Intellectual Property. Copyright and Neighboring Rights, 2002, no. 2, pp. 54-68. (In Russian).

5. Korchuganova L. V. Specifics of contracting parties siding the contractor of the commissioning agreement. Voprosy rossiiskoi yustitsii =Issues of Russian Justice, 2015, no. 2 (2), pp. 43-47. (In Russian).

6. Ruzakova O. A. Sistema dogovorov o sozdanii rezul'tatov intellektual'noi deyatel'nosti $i$ rasporyazheniya isklyuchitel'nymi pravami. Dokt. Diss. [System of agreements on creating results of intellectual activity and disposal of exceptional rights. Doct. Diss.]. Moscow, 2007. 497 p.

7. Lukyanchikova E. N. The responsibility of the author and quilt under a commissioning agreement. Patenty $i$ litsenzii. Intellektual'nye prava = Patents and Licenses. Intellectual Rights, 2012, no. 8, pp. 25-28. (In Russian).

8. Gavrilov E. P. Legal entities as authors of pieces of work. Patenty i litsenzii = Patents and Licenses, 2006, no. 12, pp. 34-41. (In Russian).

9. Stepanov S. A. (ed.). Kommentarii $k$ Grazhdanskomu kodeksu Rossiiskoi Federatsii (uchebno-prakticheskii) $k$ chasti chetvertoi [Comment of Civil Law of the Russian Federation (teaching and practical) to Part 4.]. $4^{\text {th }}$ ed. Moscow, Prospekt Publ., 2015. 456 p.

10. Sergeyev A. P. Pravo intellektual'noi sobstvennosti v Rossiiskoi Federatsii [Intellectual property right in the Russian Federation]. Moscow, Prospekt Publ., 1996. 704 p.

11. Rakhmatulina R. Sh. Avtorskii dogovor s uchastiem inostrannykh lits. Kand. Diss. [Author's contract with participation of foreign persons. Cand. Diss.]. Moscow, 2002. 156 p.

12. Sorokina L. V. Author as a party of the author's contract and of commissioning agreement. Vestnik Chelyabinskogo gosudarstvennogo universiteta. Seriya: Pravo = Bulletin of Chelyabinsk State University, Series Law, 2008, no. 22, pp. 72-76. (In Russian).

\section{Информация об авторах}

Белькова Елена Геннадьевна - кандидат юридических наук, доцент, заведующий кафедрой гражданского права и процесса, Иркутский институт (филиал) Всероссийского государственного университета юстиции (РПА Минюста России), 664011, г. Иркутск, ул. Некрасова, 4, e-mail: egbelkova@yandex.ru.

Белоусов Владилир Николаевич - старший преподаватель, кафедра гражданского права и процесса, Байкальский государственный университет, 664003, г. Иркутск, ул. Ленина, 11, e-mail: vladimir89.89@inbox.ru.

\section{Author}

Elena G. Belkova - PhD in Law, Associate Professor, Head of Chair of Civil Law and Procedure, Irkutsk Institute (branch), All-Russian State University of Justice (Ministry of Justice of the Russian Federation), 4 Nekrasov St., 664011, Irkutsk, Russian Federation; e-mail: egbelkova@yandex.ru.

Vladimir N. Belousov - Senior Lecturer, Chair of Civil Law and Procedure, Baikal State University, 11 Lenin St., 664003, Irkutsk, Russian Federation; e-mail: vladimir89.89@inbox.ru.

\section{Библиографическое описание статьи}

Белькова Е. Г. Автор как субъект договора авторского заказа / Е. Г. Белькова, В. Н. Белоусов // Baikal Research Journal. - 2017. — T. 8, № 1. — DOI: 10.17150/2411$\underline{6262.2017 .8(1) .22 . ~}$

\section{Reference to article}

Belkova E. G., Belousov V. N. Author as a subject of commissioning agreement. Baikal Research Journal, 2017, vol. 8, no. 1. DOI: 10.17150/2411-6262.2017.8(1).22. (In Russian).

\section{Baikal Research Journal}

